\title{
BARBOSA. M. G. Pró-Letramento: relações com o saber e o aprender de tutores do pólo
}

Itapecuru-Mirim/MA. 2008. 132 f. Dissertação (Mestrado em Educação Matemática) Programa de Pós-Graduação em Educação em Ciências e Matemática, Universidade Federal do Pará, Belém, 2008. (Dissertação orientada por Renato Borges Guerra).

\author{
por Adriane Elisa Dombrowski*
}

A dissertação resenhada teve por objetivo compreender as relações com o saber e o aprender de professores-tutores participantes do Programa de Formação Continuada PróLetramento em Matemática no pólo de Itapecuru-Mirim/MA ${ }^{1}$. Sua realização está ligada à prática docente do autor como professor formador do programa. Sua importância, segundo o autor, evidencia-se na busca de identificar mudanças nas ações dos professores-tutores frente ao ensino da Matemática no Ensino Fundamental (anos iniciais) apoiadas na Teoria Antropológica da Relação do Saber e do Aprender (TARSA) proposta por Bernard Charlot, e na Teoria Antropológica do Didático (TAD) de Yves Chevallard.

No primeiro capítulo, intitulado Introduzindo e Delineando a Investigação, são apresentados os pressupostos teóricos da pesquisa relativos à formação de professores, com destaque para o conceito de desenvolvimento profissional, no qual desempenha papel preponderante a necessidade interna e consciente do sujeito a fim de melhorar sua prática profissional. Situa essa investigação em relação ao pequeno número de pesquisas já realizadas sobre o tema. Manrique e André (apud BARBOSA, 2008, p. 15) afirmam que "são raros os trabalhos que focalizam mudanças associadas aos processos de formação, e mais raros ainda os que estudam as relações do docente com os conhecimentos de sua área específica.”

Ao delimitar o seu problema de pesquisa propondo-se a compreender as relações com os saberes e o aprender que professores-tutores manifestam, buscando identificar possíveis

\footnotetext{
* Mestre em Educação em Ciências e em Matemática pelo Programa de Pós-Graduação em Ciências e em Matemática da Universidade Federal do Paraná (UFPR). Professora da Escola Municipal Prof. José Moura em União da Vitória, Paraná, Brasil. Endereço: Camarista M. S. Moraes, 210, Bairro Sagrada Família, União da Vitória, CEP 84600-000, Paraná, Brasil. E-mail dombrowski.adri@ gmail.com

${ }^{1}$ O Pró-Letramento é um programa de formação continuada de professores que se subdivide em Matemática e Alfabetização e Linguagem, propondo a melhoria da qualidade da aprendizagem da leitura, escrita e matemática nos Anos Iniciais da Educação Básica. A carga horária do Programa é de 120 horas, sendo 84 horas presenciais e 36 horas a distância. O Programa é realizado pelo MEC em parceria com as Universidades que fazem parte da Rede Nacional de Formação Continuada, com a adesão de Estados e municípios. Os objetivos do PróLetramento são subsidiar a ação pedagógica dos professores dos anos iniciais da Educação Básica, contribuindo para a melhoria da qualidade do processo de ensino e da aprendizagem em língua portuguesa e matemática; promover a reflexão e a construção do conhecimento na formação continuada; desenvolver os conhecimentos necessários à compreensão da matemática e linguagem e seu processo de ensino; contribuir para uma cultura de formação continuada nas escolas; promover uma formação em rede articulando os diferentes setores ligados à Educação.
} 
mudanças na concepção e nas práticas pedagógicas e, em especial, ao objeto matemático operações com frações, o autor esclarece que o programa Pró-Letramento não tem a intenção de resolver os problemas dos professores da Educação Básica, mas de "despertá-los à busca de saberes e do saber-fazer próprios e específicos de seus campos de atuação escolar" (BARBOSA, 2008, p. 17).

O capítulo 2, TARSA e TAD: duas teorias com relação ao saber e ao aprender, apresenta o referencial teórico como suporte para a análise da investigação da pesquisa em relação às mudanças dos saberes dos professores participantes do Programa de Formação Continuada. Para o autor, a primeira das duas teorias entende as relações entre o saber e o aprender de forma ampla, considerando as relações que o indivíduo estabelece com o mundo, com o outro e com ele mesmo; já a segunda vincula essas relações ao processo de estudo da matemática. Esse capítulo também caracteriza a praxeologia ${ }^{2}$ apresentada pelos autores do Fascículo 4 e 6 do livro do Pró-Letramento em Matemática sobre as operações com as frações, evidenciando conceitos e técnicas utilizadas no ensino das frações, ressaltando, em particular, o conceito de contagem e de equivalência.

O capítulo 3, Metodologia, demonstra que a pesquisa se inclui em uma abordagem qualitativa, caracterizada pela pesquisa-ação, tal método intermediando a formação dos professores-tutores (sujeitos da investigação) e sua prática. Apresenta os instrumentos de coleta de dados - questionários, relatórios, entrevistas semiestruturadas, observações de campo, diários de estudo e cadernos de acompanhamento - para a interpretação e análise dos dados, por meio da triangulação entre eles. Juntamente com esse processo foi realizada também a análise de conteúdo.

O Programa de Formação, título do capítulo 4, descreve as características do programa como a dinâmica das seções dos fascículos e apresenta os conteúdos a eles relacionados. Essa dinâmica, conforme Barbosa (2008, p. 78) implica um contrato didático:

[...] o formador de tutor esperava que o tutor construísse grupos de trabalhos cooperativos e que estes orientassem os cursistas ao longo de toda a formação, dando-lhes suporte às suas dificuldades e inquietações, servindo ainda como elo entre formador e cursista. Além disso, o tutor esperava que o professor realizasse as atividades solicitadas pelos fascículos tanto nos encontros presenciais quanto nas atividades à distância, o qual, por sua vez, esperava que o tutor o orientasse de forma adequada. Ainda nesse sentido, o tutor almejava que o formador lhe propiciasse uma formação adequada para orientar as atividades dos cursistas e que fosse também um elo entre o tutor e os autores dos fascículos. Deste modo é que o Programa intencionava institucionalizar uma rede de formação continuada.

\footnotetext{
${ }^{2}$ Praxeologias, conceito-chave da Teoria Antropológica do Didático, concebida na década de 90 pelo francês Yves Chevallard.
} 
Também nesse capítulo, o autor caracteriza o Programa do Pró-Letramento como modalidade de Educação a Distância (EAD) e apresenta as reflexões dos professores-tutores a respeito dos conteúdos trabalhados nos fascículos, suas dificuldades, as inovações, o modo diferente de olhar. Na visão do Tutor R (apud Barbosa, 2008, p. 104) “... a ideia da matemática como um conjunto de regras ou cálculos ganhou uma nova visão: a de um instrumento ativo, dinâmico e eficaz no ensino-aprendizagem” (Diário de Bordo).

No capítulo 5, Análise dos Processos de Mudança, são apresentadas as principais mudanças percebidas: no conteúdo e no conhecimento didático dos professores-tutores do pólo de Itaperucu-Mirim/MA, analisados a partir das falas dos depoentes e dos registros realizados, segundo o olhar da TARSA e da TAD. Pode-se perceber, pelos trechos dos depoimentos dos professores-tutores, a dificuldade de alguns no trabalho com as frações. A grande maioria, porém, relata aspectos positivos, inovadores, de conceber os conteúdos, como, por exemplo, o uso da geometria para o trabalho com as operações entre as frações.

Nas Considerações Finais, Barbosa enfatiza que são perceptíveis mudanças de saberes dos professores-tutores frente ao trabalho desenvolvido tendo como base o conteúdo dos fascículos sobre o ensino das frações. Os tutores parecem ter criado ou reconhecido outras formas de organização matemática para o trabalho com os anos iniciais da Educação Básica. Foi-lhes possível, inclusive, verificar a existência de uma complementaridade entre os fascículos 4 e $6^{3}$, no que diz respeito ao ensino das frações, visto que o primeiro apresenta os conceitos e técnicas usualmente trabalhadas e o segundo justifica essas técnicas abordando, de forma integrada, os conteúdos que precedem esse capítulo. Portanto, considera-se que a mudança deu-se frente às relações estabelecidas com o outro, nos encontros de formação, com o mundo e com o próprio tutor. Nas palavras do autor, “com relação à própria Matemática, que deixa de ser entendida como saber substancial, conforme afirmado por alguns tutores, para ocupar um status de saber dinâmico que se encontra em permanente processo de (re) construção" (Barbosa, 2008, p. 116).

O autor finaliza o trabalho, convidando o leitor a pensar sobre alguns questionamentos centrados nas teorias que embasaram seu estudo: qual o sentido de estudar ou não estudar fração na escola? Qual o sentido de aprender/compreender o sistema decimal, seja na escola

\footnotetext{
${ }^{3}$ Os fascículos constituem o material didático do Pró-Letramento, elaborados por professores das Universidades que fazem parte da Rede Nacional de Formação Continuada. Os títulos dos fascículos são: Guia do Curso; Números Naturais; Operações com números naturais; Espaço e Forma; Frações; Grandezas e Medidas; Frações e Medidas; Tratamento da Informação; Resolver Problemas: o lado lúdico do ensino da Matemática; e Avaliação da aprendizagem em matemática nos Anos Iniciais. Cada fascículo é trabalhado de acordo com uma dinâmica própria, sugerida pelos autores, tendo, entretanto, 4 etapas comuns: Pensando Juntos; Trabalhando em Grupo; Roteiro de Trabalho Individual; e Nossas Conclusões.
} 
ou fora dela? Quais condições garantem que o percurso didático seja possível? Quais restrições podem impedir que essas condições sejam satisfeitas?

Barbosa estuda um programa que apresenta um olhar inovador para os conteúdos e a forma de ensinar matemática. Trata-se de um programa recente, sobre o qual muitos outros questionamentos podem ser feitos: que influências didático-pedagógicas ocorreram ou estão ocorrendo na prática de sala de aula de professores cursistas que participaram do curso de formação Pró-Letramento em Matemática? Os cursos de formação continuada estão tomando como objeto de estudo a prática do professor como ponto de partida e de chegada? É possível um curso de formação continuada contribuir de modo a serem percebidos resultados significativos para mudança do ensino da matemática ou para uma real autonomia do professor? Nesse sentido a pesquisa de Barbosa não se encerra em definitivo. Com seus questionamentos finais, o autor convida a outros estudos sobre o tema.

\section{Referências}

GONÇALVES, T. O. (Org.) MENDES, M. J. F.; GUERRA, R. B. Frações e Medidas. Brasília: SEB, SEED, UFPA, 2006. 31p. (Coleção PRÓ-LETRAMENTO, Fascículo 06)

LINS, R. C., SILVA, H. da. Frações. Brasília: MEC, SEB, SEED, UNESP, 2006. 39 p. (Coleção PRÓ-LETRAMENTO, Fascículo 04) 